\title{
Инструменты финансирования и государственной поддержки развития малых промышленных компаний
}

\author{
Павловский С.В. ${ }^{13}$
}

В статье рассматриваются тенденщии привлечения финансирования мальли промышленными предприятиями в России. Проведен анализ существующих финансовых инструментов государственной поддержки малых промышленных компаний, указаны их преимущества и недостатки. Несмотря на то что активная государственная политика последних нескольких лет существенно улучшила возможности малых промышленных компаний по привлечению необходимого финансирования, в работе выявлен дисбаланс в объемах финансовой поддержки на различных стадиях развития компании.

JEL: $G 280$

Ключевые слова на русском: малая компания, промышленность, поддержка, финансирование, государство, инфраструктура

Экономический кризис 2008-2009 годов в очередной раз подтвердил зависимость российской экономики от сырьевых отраслей и отсутствие ее достаточной диверсификации. В связи с этим активно обсуждается развитие малых предприятий, как фактор устойчивого развития российской экономики, а также формы их государственной поддержки.

Целью настоящей статьи является исследование существующих источников финансирования малых промышленных компаний и форм государственной поддержки, используемых в России. Особое внимание уделяется компаниям, имеющим потенциал быстрого роста и осуществляющим инновационную деятельность.

В 2009 году в России было зарегистрировано 1602491 малых предприятий, в том числе 165263 малых предприятий в обрабатывающей промышленности (Малое и среднее... 2011). В российской практике к малому предпринимательству относятся компании с численностью менее 100 человек и годовой выручкой менее 400 млн рублей (Постановление Правительства... 2008).

В отдельный ряд необходимо поставить малые промышленные компании, осуществляющие инновационную деятельность. Для определения инновационности деятельности можно использовать следующее определение: это процесс последовательного проведения работ по преобразованию новшества в продукцию и введение ее на рынок для коммерческого применения (Инновационная деятельность... 2011). Учитывая широкий спектр возможной инновационной деятельности (в технологиях, маркетинге, менеджменте, бизнес-процессах и т.д.), автор фокусирует внимание на технологических инновациях, которые используют малые промышленные компании. В рамках настоящей статьи это может быть новое оборудование и технологии, требующее существенных инвестиций (превышающие годовую выручку предприятия) и дающее компании конкурентные преимущества на рынке.

Удельный вес малых предприятий, осуществляющих технологические инновации, в обрабатывающей промышленности составляет $4,3 \%$, а удельный вес инновационных товаров (услуг) в общем объеме производства - всего 1,5\% (Малое и среднее... 2011). Это относится не только к малым предприятиям: удельный вес российских предприятий, занимающихся инновационной деятельностью в промышленности, составляет 7,3\%, в то время как в развитых странах этот показатель составляет от 25 до 80\% (Поляков, 2006).

Чтобы создать малую промышленную компанию, конкурентоспособную на рынках

\footnotetext{
${ }^{13}$ Менеджер проектов ГК «Ренова», преподаватель кафедры экономики и финансов фирмы НИУ ВШЭ.
} 
США, Евросоюза, Юго-Восточной Азии и Израиля, требуется не менее \$1-5 млн. Для создания проекта, ориентированного на российский рынок, в ряде случаев достаточно \$0,20,7 млн, а инвестиции в объеме $\$ 1,5-2$ млн - уже очень серьезная сумма (Каширин, 2008).

При анализе источников финансирования деятельности малых промышленных компаний их можно разделить на заемное финансирование и собственный капитал предприятия. Заемное финансирование для малого промышленного российского бизнеса доступно в России со значительными ограничениями, что связано с готовностью банков работать с малыми компаниями и стоимостью кредитов (высокие процентные ставки снижают привлекательность инвестиционных проектов).

Российский рынок венчурного капитала, который мог бы служить источником финансирования собственного капитала малых компаний, только начинает развиваться. Например, в США венчурные инвестиции в компании на «посевной» и ранних стадиях в 2007 году составили 6,5 млрд долл. (5,3 млрд долл. в 2006 году), а количество сделок - 1438 (1277 в 2006 году). Лидерами являются сферы программного обеспечения (18\% всех венчурных инвестиций в 2007 году в США), биотехнологии (17\%) и медицинские инструменты и приспособления (14\%) (National Venture, 2008).

В России объем венчурных инвестиций в 2009 году составил 124 млн долл., что более чем в 1,5 раза превышает показатель 2006 года - 75 млн долл. Количество сделок на венчурных стадиях постоянно растет - в 2009 году было профинансировано не менее 48 компаний (27 компаний в 2005 году) (Никконен, 2010). В перспективе венчурный рынок с активно работающими малыми и средними компаниями может стать одной из точек роста финансирования малых промышленных компаний.

В последние годы необходимо отметить существенное увеличение государственной поддержки источников финансирования малых промышленных предприятий, в том числе и российский рынок венчурного капитала.

Финансовые формы государственной поддержки малых промышленных компаний можно условно разделить на две группы (на основании объекта поддержки) - проектов посевной стадии (на данной стадии проверяется техническая жизнеспособность идеи) и венчурных проектов (в которые переходят проекты посевной стадии и включающие массовое производство продукции и ее коммерческую реализацию).

\section{Финансирование проектов «посевной стадии»}

Рынок частных инвестиций на посевной стадии оценивается в размере 0,5 млрд руб. в год (Каширин, 2008) и представлен бизнес-ангелами (частными лицами, самостоятельно инвестирующими собственные средства в проекты ранних стадий) и частными посевными фондами.

К государственной поддержке проектов посевной стадии можно отнести финансирование блока «Разработка технологий» в рамках Федеральной целевой программы «Исследования и разработки по приоритетным направлениям развития научнотехнологического комплекса России на 2007-2012 годы» (далее - ФЦП), деятельность Фонда содействия развитию малых форм предприятий в научно-технической сфере и Посевного фонда Российской Венчурной компании. Кроме государственных инструментов финансирования существенную роль играют частные источники средства - бизнес-ангелы и посевные венчурные фонды.

Совокупные расходы по ФЦП в 2007-2012 годах составляют 102 млрд рублей (или 17 млрд руб. в среднем ежегодно), которые малые промышленные компании могут использовать на основании контрактов на НИОКР. Осуществляется поддержка проектов в отдельных отраслях: в области индустрии наносистем и материалов - $40 \%$ от общей суммы расходов, $25 \%$ - в области живых систем, в области энергетики и энергосбережения - $18 \%$, в область рационального природопользования - 9\%, в области информационнотелекоммуникационных систем - 8\%. 
Вторым государственным источником финансирования малых промышленных компаний является Фонд содействия развитию малых форм предприятий в научнотехнической сфере, в который направляются $1,5 \%$ средств федерального бюджета на науку (1,1 млрд рублей в 2006 году) (Фонд содействия, 2011).

В 2009 году был создан Фонд посевных инвестиций Российской венчурной компании для вложений денежных средств в ценные бумаги и доли в уставных капиталах российских инновационных компаний «посевной» стадии развития. Участниками Фонда являются ОАО «Российская венчурная компания» (99\%) и Фонд содействия развитию малых форм предприятий в научно-технической сфере (1\%). Объем средств под управлением Фонда -2 млрд руб., но реально на проекты посевной стадии планируется инвестировать около 1 млрд руб. (остальное пойдет на второй раунд инвестиций и содержание фонда) (Найден, 2009). Фонд осуществляет соинвестирование средств совместно с частными инвесторами; предоставляя не более $75 \%$ от объема инвестиционной потребности компании в денежных средствах и не более 25 млн рублей на первом раунде инвестирования. В течение 2010 года было одобрено 20 проектов посевной стадии (Инвестиционный портфель, 2011). Фонд работает через венчурных партнеров, роль которых заключается в отборе проектов и гарантии инвестирования частных средств (в январе 2011 года в реестре РВК было 73 венчурных партнеров).

Ряд инициатив по содействию развития малых промышленных компаний реализован на уровне регионов. Уровень поддержки связан с уровнем развития региона - наиболее активными являются Москва, Санкт-Петербург, Республика Татарстан, в которых созданы стратегии и программы региональной политики, специальные органы и структуры для их реализации. Кроме информационной и консультационной поддержки оказывается финансовая помощь в виде субсидий и субвенций по следующим направлениям: 1) субсидии субъектов малого предпринимательства (до 2,5 млн руб. для отдельных видов деятельности); 2) компенсация части затрат на процентные займы и по лизинговым платежам (до 3,75 млн руб.); 3) компенсация расходов на участие в ярмарках; 4) возмещение части затрат, связанных с сертификацией по международным стандартам (до 0,4-0,5 млн руб.); 5) на подготовку и переподготовку кадров для работы в высокотехнологичных отраслях промышленности.

Кроме перечисленных форм поддержки имеется ряд субсидий и льгот для малых инновационных предприятий более поздних стадий развития, которые будут рассмотрены ниже.

\section{Финансирование, стадия стартап}

Общий объем средств частных венчурных фондов, доступных для инвестирования в российские малые компании стадии стартап оценивается в 5 млрд руб. (Каширин, 2008). Однако наравне с частными венчурными фондами в России действует достаточно много инструментов финансовой поддержки малых промышленных компаний стадии стартап.

Например, источником инвестиций для наукоемких компаний могут быть расходы по блоку «Коммерциализация технологий» в рамках Федеральной целевой программы «Исследования и разработки по приоритетным направлениям развития научнотехнологического комплекса России на 2007-2012 годы», которые составляют 35,3 млрд рублей (или 5,8 млрд руб. в среднем ежегодно).

Одним из основных государственных институтов поддержки малых промышленных, в первую очередь инновационных, предприятий является Российская Венчурная Компания (РВК), созданная в 2006 году по инициативе МЭРТ и выполняющая функцию фонда фондов. На РВК возложены две основные функции: отбор лучших венчурных управляющих компаний на конкурсной основе и приобретение паев венчурных фондов, создаваемых этими компаниями. Размер инвестиций в отдельный венчурный фонд в обмен на 49\% от общего числа инвестиционных паев: от 600 млн руб. до 1,5 млрд руб. 
Фонды инвестируют только в инновационные компании, чья деятельность внесена в «Приоритетные направления науки и техники РФ» или чьи продукты входят в перечень «Критические технологии РФ». Не менее чем $80 \%$ средств фонда должны быть инвестированы в компании на ранней фазе (под «ранней фазой» понимается компания с ежегодным оборотом не более 150 млн рублей на момент первого приобретения ее ценных бумаг, но фонд может участвовать и в последующих раундах инвестирования в эту компанию, независимо от дальнейшего объема продаж компании). Фонд должен инвестировать не менее чем в восемь инновационных компаний за пять лет. На настоящее время действует семь фондов с общей капитализацией 9,1 млрд рублей.

РВК также ответственно за деятельность региональных венчурных фондов. Структура региональных венчурных фондов предполагает в качестве источников финансирования средства федерального бюджета (до 25\% фонда), средства регионального бюджета (до $25 \%$ фонда) и средства частных инвесторов (не менее $50 \%$ фонда). Управляют фондами отобранные на конкурсе профессиональные управляющие компании (УК), которым из-за ограниченного размера фондов и соответственно невысокой комиссии за управление (2-3\%) разрешалось одновременно управлять несколькими фондами в нескольких регионах. К началу 2011 года были проведены тендеры по выбору управляющих компаний и создано 22 региональных венчурных фонда инвестиций в малые предприятия в научно-технической сфере с общим объемом средств 8,624 млрд руб. Фокус инвестиций региональных венчурных фондов - инновационные проекты и компании ранней стадии развития (средняя инвестиция в проект 0,5-1,5 млн долл.). Число одновременно профинансированных проектов всех фондов может составить 250-300, что в среднем составит около 50 проектов в год, при ежегодных инвестициях в объеме 1,3 млрд руб.

Отдельную нишу в поддержке малых промышленных компаний занимает Госкорпорация «Роснанотех», созданная в 2007 году с целью ведения инвестиционной и внешнеэкономической деятельности по реализации проектов в области нанотехнологий в России и за рубежом. Основной деятельностью является софинансирование в инвестиционные проекты совместно с частными инвесторами, что позволяет рассматривать не менее $30 \%$ бюджета корпорации (40 млрд рублей) в качестве потенциальных расходов на софинансирование проектов малых промышленных предприятий.

На региональном уровне действует достаточно много программ, содействующих малым компаниям, в том числе и промышленным, в привлечении кредитных ресурсов. В Москве работает НО «Фонд содействия кредитованию малого бизнеса Москвы» (О фонде, 2011), предоставляющий банкам поручительства по кредитам малых компаний до 70\% от суммы кредита и на сумму до 30 млн руб. (могут быть исключения в сторону повышения). Стоимость поручительства составляет $1,75 \%$ от суммы гарантий, но $90 \%$ этих затрат компенсируются компании из бюджета города. В рамках одной из программ Департамента поддержки и развития малого предпринимательства города Москвы из бюджета города может быть компенсировано 2/3 ставки по банковскому кредиту (Кредитные ресурсы, 2011).

Однако необходимо отметить, что данная поддержка осуществляется малому бизнесу в целом, хотя в большей степени актуальна для малых промышленных предприятий в связи с потребностью приобретения оборудования.

Подводя итоги по источникам собственных средств, доступных малым промышленным компаниям, необходимо отметить появление в 2007 году и начало работы нескольких крупных государственных институтов по поддержке малых промышленных компаний и их инновационной деятельности. Это потенциально увеличивает совокупный объем привлеченных финансовых ресурсов до 100 млрд руб., что в сравнении с существующими объемами привлеченного финансирования частными венчурными фондами в размере 5 млрд руб. видится значительным и даже избыточным при существующем на рынке количестве и качестве проектов.

Данная ситуация увеличивает риски переоценки инновационных компаний и принятие управляющими фондами неэффективных инвестиционных решений. Одним из решений 
проблемы дефицита проектов является создание нефинансовых форм поддержки малых промышленных компаний, в том числе и для посевной стадии.

Оценки объемов привлеченных средств и их источники на рынке собственного капитала в 2008-2012 годах представлены в таблице 1.

Таблица 1

Средства финансирования собственного капитала малых промышленных компаний

\begin{tabular}{|c|c|c|c|}
\hline & $\begin{array}{c}\text { Объем } \\
\text { инвестиций } \\
\text { в год / в } 1 \\
\text { проект }\end{array}$ & $\begin{array}{c}\text { Кол-во } \\
\text { проектов / } \\
\text { успешных } \\
\text { в год }\end{array}$ & Комментарий (объем инвестиций, сроки) \\
\hline $\begin{array}{l}\text { Посевная } \\
\text { стадия }\end{array}$ & $\begin{array}{l}\text { 2,5 млрд } \\
\text { руб. / - }\end{array}$ & До 500 / 30 & \\
\hline $\begin{array}{l}\text { ФЦП 2007-2012 } \\
\text { гг. (бюджетные } \\
\text { средства) }\end{array}$ & $\begin{array}{l}\text { 0,5 млрд руб. } \\
\text { / } 10 \text { млн руб. }\end{array}$ & До 50 / 10 & $\begin{array}{l}10 \% \text { проектов в рамках мероприятия } \\
\text { «Генерация знаний». Поддержка до } 10 \text { млн } \\
\text { руб. в год, до двух лет (минимум } 10 \% \\
\text { внебюджетных средств) }\end{array}$ \\
\hline $\begin{array}{l}\text { Фонд } \\
\text { содействия МП } \\
\text { НТС }\end{array}$ & $\begin{array}{l}1 \text { млрд руб./ } \\
2 \text { млн руб. }\end{array}$ & $400 /$ до 10 & $\begin{array}{l}\text { Различные сферы деятельности, в среднем } \\
400 \text { проектов в год по программе СТАРТ }\end{array}$ \\
\hline $\begin{array}{l}\text { Посевной фонд } \\
\text { РВК }\end{array}$ & $\begin{array}{l}300 \text { млн руб. } \\
\text { / } 15 \text { млн руб. }\end{array}$ & $20 / 5$ & $\begin{array}{l}\text { Объем фонда } 1 \text { млрд руб. В } 2010 \text { г. } \\
\text { одобрено } 20 \text { проектов }\end{array}$ \\
\hline $\begin{array}{l}\text { Региональные } \\
\text { власти }\end{array}$ & $\begin{array}{l}<0,5 \text { млрд } \\
\text { руб./ }<1 \text { млн } \\
\text { руб. }\end{array}$ & & 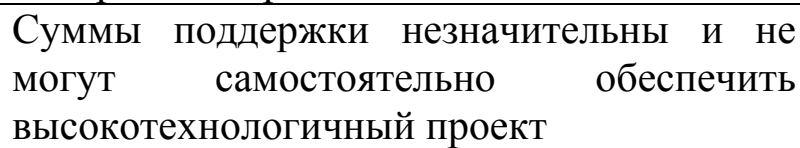 \\
\hline елы и & $\begin{array}{l}\text { 0,5 млрд руб. } \\
\text { / 2,5 млн руб. }\end{array}$ & До 10* & $\begin{array}{l}\text { Часто используют поддержку по ФЦП и } \\
\text { Фонда содействия МП НТС }\end{array}$ \\
\hline Стартап & $\begin{array}{l}20 \text { млрд руб. } \\
\text { / - }\end{array}$ & Боле & \\
\hline $\begin{array}{l}\text { ФЦП 2007-2012 } \\
\text { гг. (бюджетные } \\
\text { средства) }\end{array}$ & $\begin{array}{l}2,3 \text { млрд руб. } \\
/ \quad 150 \text { млн } \\
\text { руб. }\end{array}$ & 15 & $\begin{array}{l}20 \% \text { проектов, в рамках мероприятия } \\
\text { «Разработка технологий» (40\% крупный } \\
\text { бизнес и } 40 \% \text { институты науки) }\end{array}$ \\
\hline $\begin{array}{l}\text { ФЦП 2007-2012 } \\
\text { гг. (бюджетные } \\
\text { средства) }\end{array}$ & $\begin{array}{l}0,4 \quad \text { млрд } \\
\text { руб./ } 150 \mathrm{Mлн} \\
\text { руб. }\end{array}$ & 3 & $\begin{array}{llcl}20 \% & \text { проектов } & \text { по } & \text { блоку } \\
\text { «Коммерциализация технологий». } & \end{array}$ \\
\hline $\begin{array}{l}\text { Региональные } \\
\text { фонды }\end{array}$ & $\begin{array}{l}1,3 \text { млрд руб. } \\
/ \quad 250 \text { млн } \\
\text { руб. }\end{array}$ & 50 & $\begin{array}{l}20 \text { региональных фондов от } 120 \text { до } 800 \text { млн } \\
\text { руб. (25\% федеральный бюджет, } 25 \% \text { - } \\
\text { региональный, } 50 \% \text { - частные) }\end{array}$ \\
\hline $\mathrm{PBK}$ & $\begin{array}{l}6 \text { млрд руб. / } \\
200 \text { млн руб. }\end{array}$ & 30 & $\begin{array}{l}\text { Общий объем фондов должен превысить } 30 \\
\text { млрд руб. }\end{array}$ \\
\hline $\begin{array}{l}\text { ГК Роснанотех, } \\
\text { финансировани } \\
\text { е проектов }\end{array}$ & $\begin{array}{l}5 \text { млрд руб./ } \\
200 \text { млн руб. }\end{array}$ & 25 & $\begin{array}{lcr}\text { Планирует } & \text { утверждать } & \text { для } \\
\text { финансирования } & \text { несколько проектов в } \\
\text { месяц } & & \\
\end{array}$ \\
\hline $\begin{array}{l}\text { Финансовая } \\
\text { поддержка } \\
\text { малого бизнеса }\end{array}$ & 1 млрд руб. & $5^{*}$ & $\begin{array}{l}\text { 10\% из государственной поддержки малого } \\
\text { бизнеса }\end{array}$ \\
\hline $\begin{array}{l}\text { Бизнес-ангелы, } \\
\text { инкубаторы и } \\
\text { венчурные } \\
\text { фонды }\end{array}$ & $\begin{array}{l}1 \text { млрд руб. / } \\
100 \text { млн руб. }\end{array}$ & $10^{*}$ & $\begin{array}{l}\text { Русские технологии, ABRТ и др. ИТ-фонды } \\
\text { (до } 90 \% \quad \text { составляют средства для } \\
\text { инвестиций в сектор ИТ) }\end{array}$ \\
\hline
\end{tabular}

* Без учета инвестиций в проекты вместе с другими формами поддержки. 
Основные выводы

В настоящее время институты финансирования проектов на стадии стартап имеют потенциал ежегодных инвестиций на уровне 20 млрд руб., что позволит финансировать более 120 компаний в год. Это в 4 раза больше количества компаний, прошедших посевную стадию. Существующий уровень поддержки малых промышленных компаний на посевной стадии (кроме ИТ) не обеспечивает достаточный поток проектов для инвестиций на стадии стартап. Нераспределенные средства в фондах российской венчурной компании и «Роснанотех» свидетельствуют об избытке выделенного государственного финансирования.

Существенная доля в финансировании компаний ранних стадий приходится на государственную поддержку (более $80 \%$ на посевной стадии и $60 \%$ на стадии стартап). Это подтверждается мнением представителей государственных органов о том, что увеличение бюджетного финансирования не приводит к увеличению объема ее финансовых ресурсов в целом, а лишь вытесняет и замещает средства частного сектора (Фурсенко, 2008).

Увеличение количества проектов посевной стадии (в том числе увеличение источников финансирования проектов) возможно за счет финансовых инструментов:

- Создания дополнительных фондов посевного финансирования и вхождение венчурных фондов в более раннюю стадию проектов;

- Использование нескольких форм поддержки на проектах стадии стартап. Например, участие в одном проекте Минобрнауки или «Роснанотех», с одной стороны (их участие и экспертиза снижают технологические риски), и венчурных фондов регионов или РВК - с другой (формирование тематик и роль внебюджетного финансирования);

- Снижение капиталоемкости проектов (создания нефинансовой инфраструктуры замены необходимости создания основных средств на их аренду, лизинговых схем и т.д.).

\section{Список литературы}

1. Кредитные ресурсы // [Официальный сайт] Агентство по развитию инновационного предпринимательства, http://www.arip.ru/default2.aspx?s=0\&p=319 (дата обращения: 27.03.2011).

2. Инвестиционный портфель Фонда посевных инвестиций РВК // [Официальный сайт] Российская венчурная компания. http://www.rusventure.ru/ru/investments/fpi/portfolio.php (дата обращения: 27.03.2011).

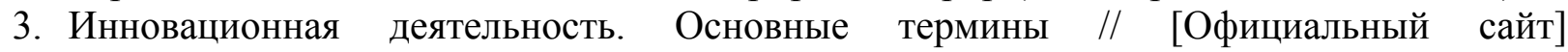
Федеральный портал по научной и инновационной деятельности. URL: http://www.sci-innov.ru/law/base_terms/ (дата обращения: 27.03.2011).

4. Каширин А.И., Семенов А.С. В поисках бизнес-ангела. Российский опыт привлечения стартовых инвестиций. М.: Вершина, 2008.

5. Никконен А. Обзор рынка прямых и венчурных инвестиций в России за 2009 год. URL: http://www.allventure.ru/lib/8/\#replies_page1 (дата обращения: 27.03.2011).

6. Найден M. РВК: построив «второй этаж», возводим первый. 18 июня 2009 г. URL: http://www.strf.ru/material.aspx?CatalogId=223\&d_no=21034 (дата обращения: 27.03.2011).

7. Малое и среднее предпринимательство в России. 2010. // [Официальный сайт] Федеральная служба государственной статистики, URL: http://www.gks.ru/wps/wcm/connect/rosstat/rosstatsite/main/publishing/catalog/statisticColl ections/doc_1139841601359 (дата обращения: 27.03.2011).

8. О фонде. // [Официальный сайт] Фонд содействия кредитованию малого бизнеса Москвы, http://fs-credit.ru (дата обращения: 27.03.2011).

9. Поляков И., Инновационная активность российских предприятий должна быть выше // Российская бизнес-газета. 10 октября 2006. № 575, с. 3. 
10. Постановление Правительства Российской Федерации от 22 июля 2008 г. № 556 (принят ГД ФС РФ 06.07.2007). URL: http://www.rg.ru/2008/07/30/biznes-dok.html (дата обращения: 27.03.2011).

11. Фонд содействия развитию малых форм предприятий в научно-технической сфере. // [Официальный сайт] Фонд содействия развитию малых форм предприятий в научнотехнической сфере. URL: http://www.fasie.ru/index.php?rid=91 (дата обращения: 27.03.2011).

12. Фурсенко А. Выступление на заседании Президиума Государственного совета РФ 18 апреля 2008 г. URL: http://www.znaniesvet.com/content/view/83/1/ (дата обращения: 27.03.2011).

13. National Venture Capital Association MoneyTree ${ }^{\mathrm{TM}}$ Report, PricewaterhouseCoopers, URL: https://www.pwcmoneytree.com/MTPublic/ns/index.jsp (дата обращения: 27.03.2011). 